\title{
An Assessment of the Credit Risk Management Mechanisms at Berhan International Bank of Hossana Branch, Ethiopia
}

\author{
Muluken Yaregal Getahun \\ $\mathrm{BA}$ in Accounting and Finance \\ Tsegaye Abie Gebeyehu \\ Assistant Professor \\ MA in English Literature, Lecturer in Wachemo University, Ethiopia
}

\begin{abstract}
The main aim this study was assessing the credit risk management mechanisms at Berhan International Bank of Hossana branch. Descriptive research design with both qualitative and quantitative methods (numerical, percentage, and tabulation) form of data analysis was employed. Both questionnaire and interview were utilized as data collecting instruments. On the other hand, purposive sampling technique was employed so as to select samples of the study. The Mechanisms used by Berhan international bank so as to manage credit risk are money saving and portfolio diversification. The bank must design credit risk management by applying two approaches required to follow to ensure the safety of each loans. The credit policy of the bank is good but it should be consider its objective for customer\& the credit policy should be subject to periodically depending on the change that may take place \&set objective standards parameter to official who grant loans.
\end{abstract}

Keywords: Risk, Credit Risk, Risk management mechanisms, Bank

DOI: $10.7176 /$ RJFA/11-7-04

Publication date: April $30^{\text {th }} 2020$

\section{Introduction}

Credit is defined as that the borrower would default on any type of debt by falling to make required payments. Credit risk is the risk that a change in the creditworthiness of counterparty affects the value of a security or a portfolio. Not receiving all promised repayments on outstanding investments such as loans and bonds due to default of the debtor are the extreme cases. When a company goes bankrupt, the counterparty usually loses the part of the market value that cannot be recovered following the insolvency.

Banks are financial institutions that are established for lending, borrowing, issuing, exchanging, taking deposits, safeguarding or handling money under the laws and guidelines of a respective country. Credit provision among their activities is the main product that banks provide to potential business entrepreneurs as a main source of generating income (Sahilemichael (2009) as cited in Pasha and Bayush, 2017)

Different financial institutions experience financial problems related with credit risk management. The problems arise due to inefficient and inadequate credit risk management system, well planned expansion derive, shortage of foreign currency and etc. The other which can be the major cause of serious banking problem is related to tax credit standards for borrower and counter parties, poor portfolio risk management, lack of attention to change in economic or other circumstance that can be lead to deterioration in the credit standard of bank counter parties.

According to Basel committee on banking supervision, (2004) as cited in Pasha and Bayush, (2017), the goal of credit risk management is to maximize the banks' risk-adjusted rate of return by maintaining credit risk exposures within acceptable parameters. Banks need to manage the credit risk inherent in the entire portfolio as well as the risk in individual credits or transactions. Effective management of credit risk is a critical component of a comprehensive approach to risk management and essential to the long-term success of any banking organizations. This is done when the banks utilize different mechanisms to manage credit risks. Therefore, the researcher assessed the mechanisms of credit risk management in case of Berhan International bank in Hossana branch.

Credit risk has been the subject of considerable research interest in Banking and Financial communities, and has recently drawn the attention of statistical researchers. The exposure to credit risk continues to be the leading source of problems in the banking industry and as a result needs to be managed. Credit risk is identified as a core pillar for the viability of banks and credit institutions.

Credit risk is the risk of loss due to a debtor's non-payment of a loan or other line of credit. Credit risk is defined as the potential that a bank and borrower or counterparty will fail to meet its obligations in accordance with agreed terms. Default occurs if the debtor is unable to meet its legal obligation according to the debt contract. The examples of default event include the bond default, the corporate bankruptcy, the credit card charge-off, and the mortgage foreclosure. Other forms of credit risk include the repayment delinquency in retail loans, the loss severity upon the default event, as well as the unexpected change of credit rating.

Credit risk management is an important aspect of a bank's success and ensures that a lending institution will not take on more risk than it can handle. Credit risk management is the lending institution's primary line of defense 
to protect itself against customers who fail to meet the terms of the loans or other credit that was extended to them. The objective of credit risk management is to minimize the risk and maximize bank's risk adjusted rate of return by assuming and maintaining credit exposure within the acceptable parameters. In a financial institution, the risk lost that resulted in the default of payment of the debtors must be expected. Banks and other financial institutions are exposed to many different type of risk, because of these, it is meaningful for a bank to keep substantial amount of capital to protect its solvency and to maintain its economic stability.

Different researches have been conducted on types of credit, credit risk management in different research sites. This means that different studies have been conducted on credit risk management in different financial institutions of Ethiopia. Let us see below these studies: Amina, et al, (2015) has conducted a study on "credit risk management of MFIS (micro-finance institutions) found in Ethiopia". Its main focus is assessing the credit risk management of MFIS found in Ethiopia and to rate these institutions according to their rank. The researchers mainly utilized secondary sources of data for collecting the data needed for their research.

The other research related to my study is a study conducted by Pagadala Suganda Devi, (2017) on credit risk management practices of MFIS in Ethiopia in Arsi University. This research mainly focuses on the practices of micro-finance found in Ethiopia in general. Goshim, (2011) has conducted a study on "performance of microfinance institutions in credit risk management; in the case of five micro-finance institutions in Addis Ababa. The research greatly focused on micro finance institutions found in Addis Ababa only. Tinishu, (2014) has studied a study on "micro finance credit rationing and loan repayment performance: a case of Omo micro-finance Konso sub branch." Its finding is that credit schemes have positive impact in improving the income, education, health and nutritional status of the borrowers. Shaik abdul mejid pasha and Bayush (2017) have studied on "Assessment of credit risk management in Ethiopian Banking." Its main focus is to assess credit risk management system in Ethiopian Banking industry of some private and government commercial banks.

Atakilt Hailu, (2015) studied on "credit risk management tools practiced in Ethiopian commercial banks." Its focus is examining and comparing the credit risk management tools practice in public and private Ethiopian commercial banks. In this research Questionnaire was utilized as data gathering tool. Rundassa and batra (2016) studied on "The impact of credit risk management on the financial performance of Ethiopian commercial banks." The main purpose of this research is to investigate the relationship between credit risk management and financial performance of Ethiopian commercial banks over a period of years 2010-2014.

However, the current research focuses on the assessment of credit risk management of Berhan International Bank of Hossana branch. This means that the research focuses on private bank of Ethiopia and the researcher deploy both primary and secondary data collection tools and utilized descriptive research design. Therefore, this research is different from the above researches by aspect of credit risk and research sites conducted.

\section{Objectives of the study}

The main objective of this study is to assess credit risk management mechanisms in the case of Berhan International Bank in Hossana branch. In addition, this research specifically attempted to achieve the following specific objectives at the end of the study.

$\checkmark \quad$ To identify what mechanisms the bank uses to assess credit risk

$\checkmark \quad$ To investigate whether the bank effectively assesses and analyzes the credit risk.

$\checkmark \quad$ To identify the potential risks relating to each of the declared aims and objectives of the bank.

\section{Methodology for the study}

This research was designed to be descriptive using both qualitative and quantitative data. Qualitative research method refers to the strategy that usually emphases words, feelings, and perceptions. On the other hand, quantitative data deals with analysis of data in the form of numeration, tabulation and percentage. In short, the research was intended to describe, and interpret the existing facts about credit risk management.

The researcher employed both primary sources of data: questionnaire and interview. Questionnaire is the most commonly used method of gathering information because it is less costly way to reach more people. It helps to collect large amount of information from large number of samples in a short period of time. Both open-ended and closed-ended types of questions were employed to collect relevant and reliable information from the target population. In addition to the questionnaire, the researcher utilized interview (semi-structured interview) to supplement the data found by questionnaire. This means that it was used to cross check the data collected by questionnaire.

The target populations of this study were professional employees of Berhan International Bank of Hossana branch. The researcher employed purposive sampling technique. This is because it helps to ponder on people who are directly involving in credit processing and administering. Besides, they can give appropriate and relevant data regarding to the study. In Berhan International Bank of Hossana branch, the total employees of the bank are 24 . Among these employees, 8 employees are concerned with credit risk management and practices. Therefore, the researcher selected those eight employees purposively. In other words, those eight employees are worthy for 
getting an information related to this study. Since the researcher employed both qualitative and quantitative research data, the researcher utilized descriptive approach in order to analyze the collected data. In short, the data were analyzed in the form of words, feeling, perception (qualitatively) and tabulation, percentage and numeration (quantitatively).

\section{Data Analysis and Presentation}

In this part, the researchers are going to make analysis and interpretation of data collected from the respondents. The data were collected through questionnaire and interview. Below is a brief discussion of the collected data. The discussion is basically made in to two ways as background of the respondents and the data collected from those respondents.

\subsection{Background of the respondent}

\subsubsection{Educational Background}

Here below are the educational backgrounds of the respondents

\begin{tabular}{|l|l|l|}
\hline \multirow{2}{*}{ Option } & \multicolumn{2}{|c|}{ No of respondents } \\
\cline { 2 - 3 } & No & Percentage \\
\hline Diploma & 5 & $62.5 \%$ \\
\hline BA degree & 3 & $37.5 \%$ \\
\hline Above first degree & - & - \\
\hline Total & 8 & $100 \%$ \\
\hline
\end{tabular}

As elaborated above, the employees of Berhan International Bank of Ethiopia at Hossana Branch in their educational status are two types. Among these, majorities $(62.5 \%)$ of the respondents are Diploma level of education and $37.5 \%$ of respondents are in the level of BA degree. There is no an employee of MA level. As a result, we can conclude that Berhan International Bank at Hossana Branch consists of employees having Diploma and BA degree level.

\subsubsection{Positions}

\begin{tabular}{|l|c|l|}
\hline \multirow{2}{*}{ Option } & \multicolumn{2}{|l|}{ No of respondent } \\
\cline { 2 - 3 } & No & Percentage \\
\hline Branch manager & 1 & $12.5 \%$ \\
\hline Marketing service officer & 7 & $87.5 \%$ \\
\hline Total & 8 & $100 \%$ \\
\hline
\end{tabular}

As explained above, both the divisional manager and branch manager in Berhan international bank hold the position of $12.5 \%$ each. In other words, $25 \%$ of the position in Berhan international bank is hold by both divisional manager and branch manager $12.5 \%$ each. $75 \%$ of the position in Berhan international bank is hold by marketing officers.

\subsubsection{Experience of the respondents}

\begin{tabular}{|l|l|l|}
\hline \multirow{2}{*}{ Option } & \multicolumn{2}{|l|}{ No of respondent } \\
\cline { 2 - 3 } & No & Percentage \\
\hline 5 year & 4 & $50 \%$ \\
\hline $5-10$ year & 3 & $37.5 \%$ \\
\hline Above 10 year & 1 & $12.5 \%$ \\
\hline Total & 8 & $100 \%$ \\
\hline
\end{tabular}

As shown in the above table, $50 \%$ of the respondents have less than 5 year work experience. $37.5 \%$ of the respondent has from 5 years to 10 years work experience in the bank. The remaining $12.5 \%$ of the respondent are above 10 years work experience. This indicates that the employees of the bank have less than 5 years working experience.

\subsection{Analysis of the Data Collected}

\subsubsection{Credit policy in the bank}

\begin{tabular}{|l|l|l|}
\hline \multirow{2}{*}{ Option } & \multicolumn{2}{|c|}{ No of respondent } \\
\cline { 2 - 3 } & No & Percentage \\
\hline Yes & 8 & $80 \%$ \\
\hline No & - & $-\%$ \\
\hline Total & 8 & $100 \%$ \\
\hline
\end{tabular}

All the respondents or $100 \%$ responded that Berhan International bank at Hossana branch has a credit policy in the bank. The credit policy is basically designed for the credit customer. The main purpose of designing the 
policy is to evaluate the credit status of the bank and to provide the frame work for the entire credit management process. According to the responses of the respondents, having a credit risk policy helps to mobilize saving. However, the bank faces some factors in not to perform the credit risk management efficiently and effectively. These are under or over financing, ineffective supervision and lack of effort and inadequate system. In other words, the bank faces risks arising from credit, interest rate, liquidity, exchange rate, transaction, compliance, strategic and image. As a result, the bank should design an effective credit risk policy in order to manage the risks related to credit and daily activities related with lending and borrowing process.

\subsubsection{Performance of credit risk management and factors affecting the performance}

\begin{tabular}{|l|l|l|}
\hline \multirow{2}{*}{ Option } & \multicolumn{2}{|c|}{ No of respondent } \\
\cline { 2 - 3 } & No & Percentage \\
\hline Yes & 5 & $62.5 \%$ \\
\hline No & 3 & $37.5 \%$ \\
\hline Total & 8 & $100 \%$ \\
\hline
\end{tabular}

$62.5 \%$ of the respondents responded that the bank performed credit risk management efficiently and effectively. However, $37.5 \%$ of the respondents responded that the bank cannot perform the credit risk management efficiently and effectively. From the theoretical point of view, every organization or institution either private or public should design credit risk management performance in order to perform the day today activity without difficulty. Therefore, it can be concluded that the bank does not absolutely perform the credit risk management efficiently and effectively. The reason for this problem is that there is ineffective supervision or administration and lack of adequate system in performing the credit risk management.

\subsubsection{Reasons in designing credit risk management}

\begin{tabular}{|l|l|l|}
\hline \multirow{2}{*}{ Items } & \multicolumn{2}{|c|}{ No of respondents } \\
\cline { 2 - 3 } & No & Percentage \\
\hline To mobilize saving & 3 & $37.5 \%$ \\
\hline To overcome the inability of payment by customer & 5 & $62.5 \%$ \\
\hline Total & 8 & $100 \%$ \\
\hline
\end{tabular}

From the above table $62.5 \%$ of the respondents responded that credit risk management is designed to overcome the inability of repayment by customer. While $37.5 \%$ of the respondents responded that the main objective of designing credit risk management is to mobilize and generate saving to their customer. It can be concluded that credit risk management, in general, is designed for mobilizing the habit of saving and to overcome the inability of payment by customer.

\subsubsection{Identifying the credit risk in advance}

\begin{tabular}{|l|l|l|}
\hline \multirow{2}{*}{ Option } & \multicolumn{2}{|c|}{ No of respondent } \\
\cline { 2 - 3 } & No & Percentage \\
\hline Yes & 6 & $75 \%$ \\
\hline No & 2 & 25 \\
\hline Total & 8 & $100 \%$ \\
\hline
\end{tabular}

As indicated above, the credit risk is $75 \%$ identified. This is done when the credit manager refers the borrower or customer profile before lending the amount of money. On the other hand, $25 \%$ of the respondents responded that the potential credit risks are not identified. As a result, the bank is going to be effective as it identifies the potential credit risks.

\subsubsection{Mechanisms of credit risk management}

\begin{tabular}{|l|l|l|}
\hline \multirow{2}{*}{ Option } & \multicolumn{2}{|c|}{ No of respondent } \\
\cline { 2 - 3 } & No & Percentage \\
\hline Money saving & 3 & $37.5 \%$ \\
\hline Portfolio Diversification & 5 & $62.5 \%$ \\
\hline Total & 8 & $100 \%$ \\
\hline
\end{tabular}

In Berhan International bank of Ethiopia of Hossana branch, there is a practice of credit risk management. This is because the credit risk management mechanisms are very crucial to minimize the credit risks of the bank. As it is elaborated in the above table, $62.5 \%$ of the respondents responded that portfolio diversification is a mechanism that is utilized in managing credit risk. It is considered as it is more essential to avoid credit risk. However, $37.5 \%$ respondents responded that money saving is employed so as to manage credit risk. On the other hand, balloon loan is more dangerous to manage credit risk. In short, Berhan International bank designs both diversification and money saving as mechanisms for managing credit risk. 


\subsubsection{The Effectiveness of Mechanisms}

\begin{tabular}{|l|l|l|}
\hline \multirow{2}{*}{ Option } & \multicolumn{2}{|c|}{ No of respondent } \\
\cline { 2 - 3 } & No & Percentage \\
\hline More effective & 2 & $25 \%$ \\
\hline Lower effective & 2 & $25 \%$ \\
\hline Moderate & 4 & $50 \%$ \\
\hline Not effective & - & - \\
\hline Total & 8 & $100 \%$ \\
\hline
\end{tabular}

The Berhan international bank of Ethiopia of Hossana branch assesses and analyzes the sources of the risk to defend early the credit risks. The above table deals with the effectiveness of the mechanisms employed in managing credit risk. As explained from the table, $50 \%$ of the respondents responded that the mechanisms utilized in managing credit risk are moderately effective. On the other hand, the same percentage $(25 \%)$ of respondents responded that the mechanisms are both more effective and lower effective. From this explanation, it can be concluded that the mechanisms employed so as to manage the credit risk are moderately effective.

\subsubsection{Problems or factors in credit risk management in the bank}

\begin{tabular}{|l|l|c|}
\hline \multirow{2}{*}{ Option } & \multicolumn{2}{|c|}{ No of respondent } \\
\cline { 2 - 3 } & No & Percentage \\
\hline Under or Over financing & 1 & $12.5 \%$ \\
\hline ineffective supervision & 1 & $12.5 \%$ \\
\hline Lack of awareness and inadequate system & 1 & $12.5 \%$ \\
\hline All & 5 & $62.5 \%$ \\
\hline Total & 8 & $100 \%$ \\
\hline
\end{tabular}

It is true that any bank in the world faces some problems or factors in managing credit risk. As the above table portrays, $62.5 \%$ of the respondents responded that all factors such as under or over financing, ineffective supervision and lack of awareness and inadequate system practiced in the bank are taken as the factors or problems exist related to credit risk management. However, $12.5 \%$ (for each items) of respondents responded as under or over financing, ineffective supervision and lack of awareness and inadequate system (system of delivery to customer) are the problems found related to credit risk management. From this view, we can deduce that the bank should tackle the stated factors so as to attain an effective management of credit risk.

\subsubsection{Approaches of credit risk}

\begin{tabular}{|l|l|l|}
\hline \multirow{2}{*}{ Option } & \multicolumn{2}{|l|}{ No of respondent } \\
\cline { 2 - 3 } & No & Percentage \\
\hline Minimum risk & 3 & $37.5 \%$ \\
\hline Diversity of risk & 5 & $62.5 \%$ \\
\hline Price risk & - & - \\
\hline Total & 8 & $100 \%$ \\
\hline
\end{tabular}

Credit risk, as indicate above, is related with other risks. For instance, $37.5 \%$ of the respondents responded that credit risk is related with minimize risk approach. On the other hand, $62.5 \%$ respondents responded credit risk is related with an approach of diversity of risk. Credit risk has not any relationship with price risk as indicated in the table above. Credit risk management often diversifies a portfolio of loans; securities and investment at a simple yet effective way of keeping problems of credit risk under control. In fact, diversity can only partially control risk and it is not an approach to credit risk that can stand independently of other approaches. In short, we can generalize that credit risk is related with minimize risk and diversity of risk approach; but the extent of diversity of risk approach is greater than the others.

\section{Conclusions and Recommendations}

\subsection{Conclusions}

This project work aimed at an assessment of credit risk management mechanisms on Berhan international Bank of Hossana branch. As a result, the following have been found as the findings of the study.

$>$ The bank has a credit policy designed to credit customer.

$>$ The performance of credit policy system in bank is somehow good. The effectiveness of performance

$>$ The credit manager performs assessing credit standing and establishing of term in regard to risk involved.

$>$ The objective of credit risk management is to mobilize saving and to overcome the inability of payment by credit customer.

$>$ The bank faces a credit risk management problem which arises by lack of awareness, applying ineffective method \& inadequate system.

$>$ The strength side of the bank would be able to identify the credit risk in advance before enter to negotiated 
to lend the money to the client.

$>$ The bank used money saving and portfolio diversification as the mechanisms of credit risk management.

\subsection{Recommendation}

Credit risk management approval needs a careful examination of project proposal because of its consequence riskiness. In the previous page the researcher concludes that one of the credit risks in the Berhan International bank is misstated financial statements which are submitted by customer. These statements are prepared through accounting techniques of window dressing to get fund from bank. To solve this problem, the bank must examine those customer financial statements which are prepared for other purpose such as for government tax etc...

$>$ The credit risk management is weak within the practical situation so, the bank should design strong \& competent credit management because credit risk management is advantageous for proper and good mobilization of funds.

$>$ The bank must design credit risk management by applying two approaches required to follow to ensure the safety of each loans.

$>$ The credit policy of the bank is good but it should be consider its objective for customer\& the credit policy should be subject to periodically depending on the change that may take place \&set objective standards parameter to official who grant loans.

$>$ Even if, the bank may not collect its credit with the specified period, the bank must be ready to make change like.

- Increase the grace of period of these activities which require long period

- Appreciate customer which pay on time by giving them a discount and having strict follow up for those customer which do not pay on time

\section{Reference}

Amina, et al, (2015): Credit risk management of MFIS found in Ethiopia.

Atakilt Hailu, (2015): Credit risk management tools practiced in Ethiopian commercial banks.

Goshim, (2011): Performance of micro-finance institutions in credit risk management; in the case of five microfinance institutions in Addis Ababa.

Pagadala Suganda Devi, (2017): Credit risk management practices of MFIS in Ethiopia, Arsi University.

Rundassa and batra (2016): The impact of credit risk management on the financial performance of Ethiopian commercial banks.

Sahlemichael Mekonnen, 2009: Credit Risk Management System of Ethiopian Commercial Banks: Addis Ababa, AAU.

Shaik Abdul Mejid Pasha and Bayush Mentesinot (2017): Assessment of credit risk management in Ethiopian Banking. Arba Minich University.

Sofia, 2010: Overview of Credit Risk Management practice: The banking perspective

Tinishu, (2014): Micro-finance credit rationing and loan repayment performance: a case of Omo micro-finance Konso sub branch." 